\title{
Experimental Study on the Salinity Tolerance of Macrobrachium idae Larvae
}

\author{
P. Subramanian, S. Sambasivam and K. Krishnamurthy \\ Centre of Advanced Study in Marine Biology, Annamalai University, Parangipettai 608 502, Tamil Nadu, India
}

\begin{abstract}
The 'freshwater' prawn Macrobrachium idae Heller tolerates in nature and culture varying salinities typical of a brackish or estuarine environment. It holds promise as an amenable species for aquaculture in rural areas of developing countries. Experiments were conducted on larval survival and to determine optimum environmental conditions. During early development, larvae preferred salinities from 5 to $20 \% \mathrm{~S}$. In these salinities all larvae moulted after $24 \mathrm{~h}$; their median tolerance limit (120 h) was $27 \% \mathrm{~S}$.
\end{abstract}

\section{INTRODUCTION}

In recent years, aquaculture as an enterprise has assumed global importance. Though Macrobrachium idae is a freshwater prawn, it is facultative euryhaline, and abundant during monsoon (October and November) and post-monsoon (January and February) seasons at Parangipettai (Porto Novo, Coromandel coastline, Tamil Nadu, India) in estuarine, backwater and mangrove niches. Its migration into brackish water for spawning and the return of its juveniles upstream to freshwater has been investigated by Visco (1920), Nataraj (1947), Panikkar (1967), and George (1969). The species has a wide scope for aquaculture ventures in tropical regions. In view of its economic importance we have studied responses of larvae to salinity changes.

\section{MATERIAL AND METHODS}

Berried Macrobrachium idae were collected during December from the estuary and brought to the laboratory for spawning. Prawns were kept in plastic tubs of $40 \mathrm{l}$ capacity, filled with glasswool-filtered clean estuarine water (collected from the same spot as the prawns) of $18 \% \mathrm{~S}$ and fed freshly-chopped clam meat. Active larvae were sorted out 6 to $8 \mathrm{~h}$ after hatching for experiments. The larvae were directly transferred to 9 different test salinities, ranging from 0 to $40 \% \mathrm{~S}$ (increasing the salinity by $5 \%$ at each step) in $500 \mathrm{ml}$ glass beakers. Each beaker contained 20 larvae and was filled with water of test salinity. For carrying out

(C) by Inter-Research each experiment, two replicates were run simultaneously with the same number of larvae. A control (18\% S) was run simultaneously. For zero salinity, dechlorinated tap water was used. Salinity adjustments, whenever required, were made using dechlorinated tap water and/or sea water. During the experimental period, aeration was provided and the larvae were fed freshly hatched Artemia salina nauplii. All experiments were carried out under normal laboratory light conditions and at room temperature $\left(25^{\circ} \pm 2 \mathrm{C}^{\circ}\right)$ for $120 \mathrm{~h}$.

Daily observations were made on larval behaviour and survival. Larval mortality was confirmed only after observing the cessation of heart beat of the moribund zoea under a binocular microscope. Dead larvae were removed immediately. The 'test water' was replenished daily with freshly prepared water of respective salinity. In absence of significant difference between the values of experiment and replicates, all values were pooled for calculating the mean. The mean percentage of mortality of larvae was recorded at different time intervals to determine the median tolerance limits (TLm) after Litchfield and Wilcoxon (1949). Results of experiments conducted in freshwater were not used to obtain dose effect curves.

\section{RESULTS}

After $10 \mathrm{~d}$ in captivity berried prawn tended to incline to one side of the container. Rapid, discontinuous lashing of their pleopods provided aeration, 
Table 1. Macrobrachium idae. Mean percentage survival of larvae reared in different salinities over different exposure periods. At each salinity a total of 60 zoeae were tested

\begin{tabular}{|c|c|c|c|c|c|c|}
\hline \multirow{2}{*}{$\begin{array}{l}\text { Salinities } \\
(\mathrm{S} \%)\end{array}$} & \multicolumn{5}{|c|}{ Percentage survival after } & \multirow{2}{*}{$\begin{array}{l}\text { Total number of zoeae } \\
\text { surviving after } 120 \mathrm{~h}\end{array}$} \\
\hline & $24 \mathrm{~h}$ & $48 \mathrm{~h}$ & $72 \mathrm{~h}$ & $96 \mathrm{~h}$ & $120 \mathrm{~h}$ & \\
\hline 18 (control) & 100 & 100 & 100 & 100 & 100 & 60 \\
\hline $0^{\circ}$ & 100 & 70 & 50 & 20 & 5 & 3 \\
\hline 5 & 100 & 100 & 100 & 100 & 100 & 60 \\
\hline 10 & 100 & 100 & 100 & 100 & 100 & 60 \\
\hline 15 & 100 & 100 & 100 & 100 & 100 & 60 \\
\hline 20 & 100 & 100 & 100 & 100 & 87 & 52 \\
\hline 25 & 100 & 100 & 100 & 100 & 67 & 40 \\
\hline 30 & 100 & 100 & 97 & 93 & 27 & 16 \\
\hline 35 & 100 & 93 & 87 & 80 & 20 & 12 \\
\hline 40 & 93 & 57 & 10 & 7 & 0 & 0 \\
\hline \multicolumn{7}{|c|}{ - $0 \%=$ Dechlorinated capwater } \\
\hline
\end{tabular}

stimulating and accelerating embryonal stretching movements (Katre and Pandian, 1972).

In the different test salinities Macrobrachium idae larvae moulted normally $24 \mathrm{~h}$ after hatching. The zoeae behaved normally when exposed up to $16 \mathrm{~h}$ to $40 \% \mathrm{~S}$; thereafter they sank for a brief while to the bottom and again attempted to surface. A moribund condition of $6-10 \mathrm{~h}$ preceded death in lethal salinities. During that period, the zoea gradually changed from a 'transparent hue' to an 'opaque white' in colour before they eventually died.

Figure 1 shows the percentage of mean survival (mean of one experiment and two replicates) of Macrobrachium idae larvae exposed to different salinities. Figure 2 illustrates the cumulative percentage (calculated for $120 \mathrm{~h}$ ) of zoea mortality. Table 1 lists the mean percentage of survival in different test salinities at varying exposure times and Table 2 the observed mortality in different salinities and the corresponding $95 \%$ confidence limits.

In $40 \% \mathrm{~S}$, mortality began after $20 \mathrm{~h}$; all zoeae had died after $120 \mathrm{~h}$. In $35 \% \mathrm{~S}$ and in zero salinity, the

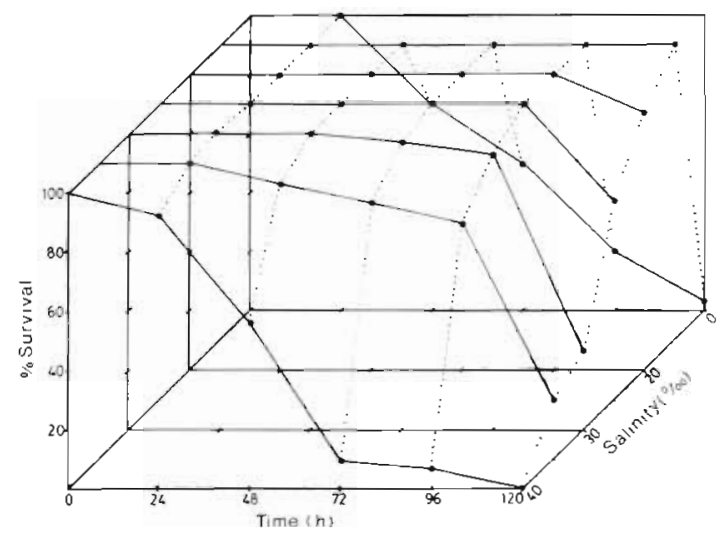

Fig. 1. Macrobrachium idae. Percentage of mean survival of larvae exposed to different salinities over different periods of time zoeae approached death from 48 h onward; after $120 \mathrm{~h}$ their survival was $20 \%$ and $5 \%$, respectively. In $30 \% \mathrm{~S}$, death began to occur after $72 \mathrm{~h}$ and only $27 \%$ of zoeae were alive after $120 \mathrm{~h}$. No mortality was encountered in the range 5-25\% S until $96 \mathrm{~h}$. Beyond $96 \mathrm{~h}$ and after $120 \mathrm{~h} 87 \%$ and $67 \%$ of the zoeae survived in $20 \%$ and $25 \% \mathrm{~S}$. No mortality or moribund states were observed in the controls. In salinities of 5 , 10 and $15 \%$ S, all zoeae behaved normally over the entire duration of our experiments. Here, the $120 \mathrm{~h}$ TLm value was $27 \% \mathrm{~S}(25.5$ to $28.6 \% \mathrm{~S})$.

\section{DISCUSSION}

Our study reveals that the optimum salinity range for larval Macrobrachium idae, regarding survival and development, lies between 5 and $20 \% \mathrm{~S}$. The best salinity for survival appears to be between 5 and $15 \% \mathrm{~S}$. Gravid females appear to prefer a medium salinity of $18 \% \mathrm{~S}$ for laying and hatching their eggs. Similar findings were reported for $M$. rosenbergii whose larvae and adults are 'euryhaline to a considerable degree' (Goodwin and Hanson, 1974) and tolerated salinities up to $21 \% \mathrm{~S}$ (Fujimura, 1974; Goodwin and Hanson, 1974). Post larval blood concentrations of

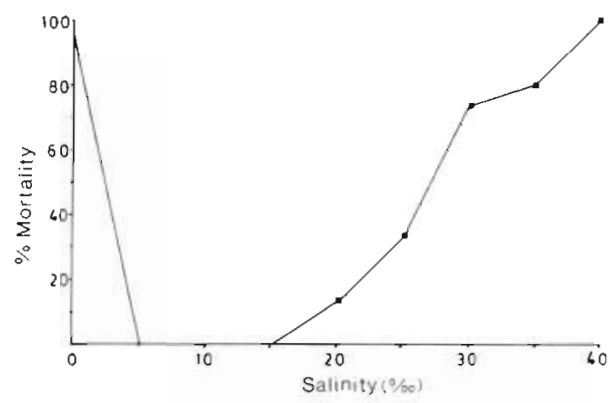

Fig. 2. Macrobrachium idae. Cumulative percentage of mortality after $120 \mathrm{~h}$ of larvae exposed to different salinities 
Table 2. Macrobrachium idae. Salinity effects on larvae. Concentrations-effect curve. TL = Tolerance limit

\begin{tabular}{|c|c|c|c|c|c|}
\hline $\begin{array}{l}\text { Salinity } \\
\left(\% \%_{00} \mathrm{~S}\right)\end{array}$ & $\frac{\text { No. dead }}{\text { No. tested }}$ & $\begin{array}{c}\text { Mortality } \\
(\% / 0)\end{array}$ & $\begin{array}{l}\text { Expected } \\
\text { values }\end{array}$ & $\begin{array}{c}\text { Difference between } \\
\text { observed \& } \\
\text { expected values }\end{array}$ & $\mathrm{Chi}^{2}$ \\
\hline 40 & $60 / 60$ & $100(97.4)$ & 92 & 5.4 & 0.0380 \\
\hline 35 & $48 / 60$ & 80 & 83 & 3.0 & 0.0060 \\
\hline 30 & $44 / 60$ & 73.3 & 65 & 8.3 & 0.0300 \\
\hline 25 & $20 / 60$ & 33.3 & 39 & 5.7 & 0.0130 \\
\hline 20 & $8 / 60$ & 13.3 & 14 & 0.7 & 0.0010 \\
\hline 15 & $0 / 60$ & $0(0.7)$ & 1.6 & 0.9 & 0.0045 \\
\hline \multicolumn{6}{|c|}{$\begin{array}{l}\text { TL } 16=35.5 \% \mathrm{~S} \\
\text { TL } 84=20.5 \% \mathrm{~S} \\
\text { TLm or TL } 50=27 \% \mathrm{~S} \\
95 \% \text { Confidence limit }=28.6-25.5 \% \mathrm{~S} \\
\text { Slope ' } \mathrm{S} \text { ' }=1.316\end{array}$} \\
\hline
\end{tabular}

M. rosenbergii are hyperosmotic to ca 17 or $18 \% \mathrm{~S}$, but hypoosmotic at higher salinities; they died within few days at $30 \%$ (Sandifer et al. 1975).

Our study further reveals that at $30 \% \mathrm{~S}$ Macrobrachium idae larvae exhibit signs of mortality after $72 \mathrm{~h}$; between 96 and $120 \mathrm{~h}, 73 \%$ died. In freshwater, larval mortality began after $48 \mathrm{~h}$ and only $5 \%$ of the larvae remained alive after $120 \mathrm{~h}$. Similarly, survival of $M$. rosenbergii larvae was observed to be limited in freshwater to only about $5 \mathrm{~d}$ (Goodwin and Hanson, 1974). In $M$. idae, the calculated TLm value (for $120 \mathrm{~h}$ ) revealed that only $50 \%$ of the larvae survived in $27 \%$ S. Hence, $M$. idae must be classified as euryhaline. It shows a preference for lower salinities for spawning, as well as for the survival, growth and development of its larvae. Commercial cultivation of $M$. idae holds considerable promise in the vast brackish water inland areas of the tropics.

Acknowledgements. We are thankful to Professor R. Natarajan, Director, for the facilities provided. Our thanks are also due to the University Grants Commission, New Delhi, for financial support of the project 'The culture of the prawn, Penaeus indicus' and for the award of research fellowships to two (P. S. and S. S.) of us.

\section{LITERATURE CITED}

Fujimura, T. (1974). Development of a prawn industry, development of a rearing technique for the giant long- legged prawn Macrobrachium rosenbergii; Quarterly Progress Reports under the Commercial Fisheries Development Act, National Marine Fisheries Service, March, 1967; Jan., 1968; Feb., 1969

George, M. J. (1969). Systematics - Taxonomic consideration and general distribution. Bull. Cent. mar. Fish. Res. Int. 14: $5-49$

Goodwin, H. L., Hanson, J. A. (1975). Aquaculture of the freshwater prawn Macrobrachium species. The Oceanic Institute, Waimanalo, Hawaii

Katre, S., Pandian, T. J. (1972). On the hatching mechanism of a fresh water prawn Macrobrachium idae. Hydrobiologia 40: $1-17$

Ling, S. W. (1969). The general biology and development of Macrobrachium rosenbergii (deMan). FAO Fish Rep. 57 (3): 589-606

Litchfield, J. T., Wilcoxon, F. (1949). A simplified method of evaluating dose-effect experiments. J. Pharmaco. exp. Ther. 96: 99-113

Nataraj, S. (1947). Preliminary observations on the bionomics, reproduction and embryonic stages of Palaemon idae Heller. Rec. Indian Mus. 45: 86-96

Panikkar, N. K. (1967). Osmotic behaviour of shrimps and prawns in relation to their biology and culture. FAO Bull. Fr. BCSP $/ 67 / \mathrm{E} / 25$

Sandifer, P. A., Smith, T. I. J. (1970). Development of a crustacean mariculture programme at South Carolina's marine resources research institute. In: Proceedings of the fifth annual workshop world mariculture society, pp. 431-439

Sandifer, P. A., Hopkins, J. S., Smith, T. I. J. (1975). Observations on salinity tolerance and osmoregulation in laboratory - reared Macrobrachium rosenbergii postlarvae (Crustacea: Caridea). Aquaculture 6: 103-114

Visco, P. Jr. (1920). Report of the biologist. Louisiana Department of Conservation. Fourth Biennial Report 1918-1920: $120-130$ 